\title{
Comparison of the effects of lateral and sitting position during induction of spinal anaesthesia with plain levobupivacaine in caesarean section
}

\author{
Sreekanth R. ${ }^{1}$, Sachin Ramesh Totawar ${ }^{2, *}$ \\ ${ }^{1}$ Senior Resident, ${ }^{\mathbf{2}}$ Associate Professor, Dept. of Anaesthesiology, Dr. Shankarrao Chavan Government Medical College, \\ Nanded, Maharashtra, India
}

*Corresponding Author:

Email: sachin.totawar@gmail.com

Received: $07^{\text {th }}$ February, 2017

Accepted: $13^{\text {th }}$ May, 2017

\begin{abstract}
Introduction: Spinal anaesthesia is a commonly employed anaesthetic technique for caesarean section. Levobupivacaineis a new long acting amide, local anaesthetic. Only few studies have investigated spinal anaesthesia using plain levobupivacaine in obstetrics.Levobupivacaine has all the desirable qualities of local anesthetics like with rapid onset, wide margin of safety, adequate surgical anaesthesiawith minimal side effects on the mother as well fetus.

Aim and Objectives: To study the effects of spinal anaesthesia induced in lateral and sitting position during caesarean section using plain levobupivacaine.

Materials and Methods: The study was carried out in tertiary care centre between Jan. 2014-June 2015 on total 100 patients posted for caesarean section. The parameters observed included- Sensory blockades onset and its duration, motor blockades onset, duration and degreeand quality of anaesthesia.

Results: In group L (that received plain levobupivacainein left lateral position) $90 \%$ of patients had onset to T10 in 3-4 minutes. Onset of sensory block in group $\mathrm{L}$ was in $3.62 \pm 0.09$ minutes and $3.77 \pm 0.11$ minutes in group $\mathrm{S}$ (those received plain levobupivacainein sitting position). Two dermatome regression in group L were $80.96 \pm 1.75$ min and in group $\mathrm{S}$ were $81.44 \pm$ 1.70 minutes. Motor onset in group $\mathrm{L}$ and $\mathrm{S}$ was $5.747 \pm 0.375$ minutes and $5.876 \pm 0.396$ min respectively. Total duration of motor block in group $\mathrm{L}$ was $157.90 \pm 3.23$ minutes.

Conclusion: We concluded that $12.5 \mathrm{mg}$ dose of isobaric levobupivacaine $0.5 \%$ provides effective spinal anaesthesia, ensures haemodynamic stability, excellent quality of sensory and motor block with no influence of gravity on the spread in sitting as well as lateral position.
\end{abstract}

Keywords: Caeserrian, Lateral, Levobupivacaine, Spinal.

\section{Introduction}

Spinal anaesthesia was introduced into clinical practice by August Karl Gustav Bier and his assistant August Hilderbrandt in the year 1898 when general anaesthesia was the only other alternative available. ${ }^{1}$

Subarachnoid block (SAB) is the most common anesthesia technique for performing caesarean section. ${ }^{2}$ The technique is simple, safe, reliable and has rapid onset. Epidural anaesthesia was considered the preferred method for caesarean delivery but the limitation was delayed onset in urgent caesarean section. ${ }^{3} \mathrm{SAB}$ in pregnant women is associated with increase in incidence of hypotension due to higher sympathetic block, which is further aggravated by aortocaval compression of gravid uterus. ${ }^{3}$ Maternal blood pressure can be maintained with, left lateral tilt, low dose vasopressors and preloading of fluid. The ideal drug for $\mathrm{SAB}$ would provide rapid onset, adequate surgical anaesthesia together with greater safety margin, early ambulation and ability to void to allow early discharge.

Many local anaesthetics have been used for spinal anaesthesia in various strengths and volumes. Lignocaine was the most widely used local anaesthetic for spinal anaesthesia in caesarean section because of its faster onset and shorter duration of action. But the incidence of transient neurologic symptoms (TNS) with lignocaine made it less popular. ${ }^{4,5}$ Bupivacaine is long actingand is one of the most commonly used local anaesthetic for SAB but its accidental intravenous injection may cause cardiotoxicity and severe hypotension. ${ }^{6}$ Levobupivacaine, the pure $\mathrm{S}(-)$ enantiomer of racemic bupivacaine, is a new long acting amide, local anaesthetic, ${ }^{7}$ with a wide margin of safety, low cardiotoxicity and is equipotent to bupivacaine. Since levobupivacaine has all the advantages of bupivacaine it may be an ideal local anaesthetic for SAB.

Local anaesthetics which are hyperbaric as compared to cerebrospinal fluid produce more reliable spread when injected intrathecally. ${ }^{8}$ Though it is reliable but may be associated with risk like transient neurologic symptoms. ${ }^{4,5}$ Only few studies have investigated obstetric spinal anaesthesia using plain levobupivacaine. ${ }^{9}$ The density of cerebrospinal fluid in obstetric patients is comparatively lower and plain levobupivacaine has been shown to be truly isobaric with respect to cerebrospinal fluid of pregnant women. This property may translate to a more predictable spread of drug. Hence, we have used plain 
levobupivacaine for study. Dose requirement of local anaesthetic agent is low in pregnant when compared to non-obstetric patients. Levobupivacaine possesses all the desirable qualities with rapid onset, wide margin of safety, adequate surgical anaesthesia and has no side effects on the mother as well on the baby. Hence it can be safely used in caesarean sections. ${ }^{9}$

Despite increasing use of $\mathrm{SAB}$, the position during initiation is still at the discretion of the anaesthesiologist. Maternal position, by influencing the spread of local anaesthetic, may affect the speed of onset of sensory block. ${ }^{10}$ The delay in positioning the parturients may affect the intrathecal distribution of local anaesthetics. Inadvertent cranial extension of sympathetic and sensory block has been reported for isobaric as well as hyperbaric local anaesthetics. ${ }^{11}$ Isobaric solutions have minimal changes on vital parameters during position change. ${ }^{9}$ So we have conducted this randomized, single blinded study to determine the effects of spinal anaesthesia in the lateral and sitting position of the pregnant patients, following the injection isobaric levobupivacaine $0.5 \%$ into the subarachnoid space.

\section{Aims and Objectives}

To study the effects of lateral and sitting position when administering sub arachnoid block for caesarean section using plain levobupivacaine. The parameters studied included-Onset and Regression of analgesia at $\mathrm{T} 10$ and T6, maximum cephalad spread of analgesia, duration of sensory and motor blockade, quality of anaesthesia, Apgar score and postoperative complications if any.

\section{Materials and Methods}

After approval from the ethical committee of the institution, randomized control study was conducted at tertiary care centre between Jan. 2014-June 2015.The study included total 100 patients belonging to ASA grade I and II posted for caesarean section. The exclusion criteria included history of allergy or sensitivity to amide type local anaesthetics, altered coagulation status, infection at puncture site, multiple pregnancy, maternal cardiac disease, suspected fetal abnormality, complicated pregnancy and all patients contraindicated for SAB.

On the day of surgery all standard monitors (NIBP, ECG, pulse oximeter) were attached. Under all aseptic precautions SAB was given in L3-L4 interspace with 25 Gzquinckes spinal needle.

The patients were randomly allocated into two groups as follows:

GROUP-L: 50 patients who received plain levobupivacaine $0.5 \%(2.5 \mathrm{ml}) 12.5 \mathrm{mg}$ in left lateral position and GROUP-S:50 patients who received plain levobupivacaine $0.5 \%(2.5 \mathrm{ml}) 12.5 \mathrm{mg}$ given in sitting position and remained in same position for 2 minutes before supine position.

Patients were slowly positioned into supine horizontal position with left lateral tilt. Surgery was started when loss of pinprick sensation to T6 was achieved. Every patient was evaluated at every 2 minutes till 15 minutes then every 5 minutes till 30 minutes and then every 15 minutes till operation was completed and thereafter every 2 hours in postoperative period by noting the vital parameters.

Parameters observed includes the onset and duration of sensory blockade was subjectively studied by pin prick method at umbilicus (T10) level,(T6) level and maximum cephalad spread also noted. Two dermatome regression, at T10 and regression to level S2 was the total duration of sensory block. The onset, duration and degree motor blockade was assessed by straight leg rising while lying supine and was graded according to modified bromage scale $(\mathrm{mBs}) .{ }^{12}$ Onset of motor block was defined as time taken from injection of drug to achievement of $\mathrm{mBs} 3$, that is inability to lift hip, knee and ankle. Duration of motor block was defined as the time taken from injection of drug to ability of patient to again move hip against gravity $(\mathrm{mBs} 0)$.The quality of anaesthesia was assessed depending upon the subjective feeling of pain, that patient could tolerate and need of supplemental analgesic. Conversion to general anaesthesia was considered as failure of anaesthesia.

\begin{tabular}{|l|l|}
\hline Quality of Anaesthesia \\
\hline Excellent & $\begin{array}{l}\text { Patient perceived no pain and no additional } \\
\text { analgesia required }\end{array}$ \\
\hline Good & $\begin{array}{l}\text { Patient perceived mild pain that she can tolerate } \\
\text { and noneed of supplementation }\end{array}$ \\
\hline Fair & $\begin{array}{l}\text { Patient perceived pain and need additional } \\
\text { intravenous analgesia and sedation }\end{array}$ \\
\hline Poor & $\begin{array}{l}\text { Patient perceived severe pain and needs to be } \\
\text { converted into general anaesthesia }\end{array}$ \\
\hline
\end{tabular}

Grading of APGAR score was done at 1 and 5 minutes after birth. 


\section{Results}

At the end of study, the data was tabulated and the patient characteristics noted and data was subjected to statistical analysis.

Table I: Age (In years) Distribution

\begin{tabular}{|l|c|c|c|c|}
\hline \multirow{2}{*}{\begin{tabular}{c}
\multirow{2}{*}{$\begin{array}{c}\text { Age (In } \\
\text { Years) }\end{array}$} \\
\cline { 2 - 5 }
\end{tabular}} & $\begin{array}{c}|c| \\
\text { Number of } \\
\text { Patients }\end{array}$ & $\begin{array}{c}\text { Percentage } \\
(\boldsymbol{\%})\end{array}$ & $\begin{array}{c}\text { Number of } \\
\text { Patients }\end{array}$ & $\begin{array}{c}\text { Percentage } \\
(\boldsymbol{\%})\end{array}$ \\
\hline $18-26$ & 42 & $84.0 \%$ & 41 & $82.0 \%$ \\
\hline $27-35$ & 08 & $16.0 \%$ & 09 & $18.0 \%$ \\
\hline Total & 50 & $100.0 \%$ & 50 & $100.0 \%$ \\
\hline
\end{tabular}

The patients were in the age group between 18 and 36 years.84\%patients in group L and $82 \%$ in group S, belongs to the age group 18-26 years of age. Mean age of patients in group L was $23.38 \pm 0.44$ in years and $24.22 \pm 0.46$ in years in group $\mathrm{S}$ respectively. $\mathrm{p}$ value $>0.05$ and was not significant.

Table II: Distribution of Time for Onset of Sensory block to T10 in minutes

\begin{tabular}{|c|c|c|c|c|}
\hline \multirow{3}{*}{$\begin{array}{c}\text { Time of } \\
\text { onset to T10 } \\
\text { (In minutes) }\end{array}$} & \multicolumn{4}{|c|}{ Groups } \\
\hline & \multicolumn{2}{|c|}{$\mathbf{L}$} & \multicolumn{2}{|c|}{$\mathbf{S}$} \\
\hline & $\begin{array}{c}\text { Number of } \\
\text { Patients }\end{array}$ & $\begin{array}{c}\text { Percentage } \\
(\%)\end{array}$ & $\begin{array}{l}\text { Number of } \\
\text { Patients }\end{array}$ & $\begin{array}{c}\text { Percentage } \\
(\%)\end{array}$ \\
\hline $1-2$ & 00 & $00 \%$ & 00 & $00 \%$ \\
\hline $3-4$ & 45 & $90 \%$ & 46 & $92 \%$ \\
\hline $5-6$ & 05 & $10 \%$ & 04 & $08 \%$ \\
\hline Total & 50 & $100.0 \%$ & 50 & $100.0 \%$ \\
\hline
\end{tabular}

In group L $90 \%$ of patients had onset to T10 in 3-4 minutes and 10\% had onset to T10 in 5-6 minutes. In group S 92\% of patients had onset to T10 in 3-4 minutes and 8\% had onset to T10 in 5-6 minutes. Onset of sensory block in group L $3.62 \pm 0.09$ in minutes and $3.77 \pm 0.11$ in minutes in group S. P value 0.341 is statistically not significant.

Table III: Two Dermatome Regression

\begin{tabular}{|l|l|l|l|l|l|l|l|}
\hline Groups & $\mathbf{n}$ & Min & Max & $\begin{array}{c}\text { Mean } \pm \\
\text { S.D. }\end{array}$ & $|\mathbf{Z}|$ & P & $\begin{array}{c}\text { Decision based } \\
\text { on p-value }\end{array}$ \\
\cline { 1 - 5 } L & 50 & 78 & 85 & $80.96 \pm 1.75$ & & & \\
\cline { 1 - 1 } & 50 & 78 & 85 & $81.44 \pm 1.70$ & -1.389 & 0.164 & Non-Significant \\
\hline
\end{tabular}

Two dermatome regressionin group $\mathrm{L}$ were $80.96 \pm 1.75$ minutes and Two dermatome regression in group $\mathrm{S}$ were $81.44 \pm 1.70$ minutes. $\mathrm{P}$ value 0.164 were not statistically significant.

Table IV: Regression T10 (min.)

\begin{tabular}{|l|c|c|c|c|c|c|c|}
\hline Groups & $\mathbf{n}$ & Min & Max & Mean \pm S.D. & $|\mathbf{Z}|$ & $\mathbf{P}$ & $\begin{array}{c}\text { Decision based } \\
\text { on p-value }\end{array}$ \\
\cline { 1 - 2 } & 50 & 155 & 162 & $157.12 \pm 1.73$ & & & Non-Significant \\
\hline S & 50 & 152 & 163 & $157.92 \pm 2.56$ & -1.828 & 0.067 & Non \\
\hline
\end{tabular}

Sensory regression to T10 in group $\mathrm{L}$ is $157.12 \pm 1.73$ minutes and Sensory regression to T10 in group $\mathrm{S}$ is $157.92 \pm 2.56$ minutes. P value obtained is 0.067 and is not statistically significant. Sensory regression to S2 in group L is $242.24 \pm 1.93$ minutes and Sensory regression to S2 in group S is $242.94 \pm 3.48$ minutes. P value obtained is 0.213 and is not statistically significant.

Table V: Motor onset (min.)

\begin{tabular}{|l|c|c|c|c|c|c|c|}
\hline Groups & $\mathbf{n}$ & Min & Max & Mean \pm S.D. & $|\mathbf{Z}|$ & $\mathbf{P}$ & $\begin{array}{c}\text { Decision based } \\
\text { on p-value }\end{array}$ \\
\cline { 1 - 6 } L & 50 & 5.12 & 6.45 & $5.747 \pm 0.375$ & & & \\
\cline { 1 - 1 } & 50 & 5.12 & 6.53 & $5.876 \pm 0.396$ & -1.674 & 0.094 & Non-Significant \\
\hline
\end{tabular}


Motor onset in group $\mathrm{L}$ is $5.747 \pm 0.375$ minutes and Motor onset in group $\mathrm{S}$ is $5.876 \pm 0.396$ minutes. $\mathrm{P}$ value is 0.094 and is not statistically significant. Total duration of motor block in group L is $157.90 \pm 3.23$ minutes and in group $\mathrm{S}$ is $158.52 \pm 2.37$ minutes. $\mathrm{P}$ value is 0.234 and is not statistically significant.

Table VI: APGAR 1 Min. Score of Groups

\begin{tabular}{|l|c|c|c|c|c|}
\hline \multirow{1}{*}{ Groups } & \multicolumn{2}{|c|}{ APGAR Score } & Total & p-value & $\begin{array}{c}\text { Decision } \\
\text { (Based on p-value) }\end{array}$ \\
\cline { 2 - 4 } & $\mathbf{8}$ & $\mathbf{9}$ & & & \multirow{2}{*}{0.7407} \\
\hline L & 06 & 44 & 50 & Non-Significant \\
\hline S & 04 & 46 & 50 & & \\
\hline Total & 10 & 90 & 100 & & \\
\hline
\end{tabular}

APGAR score at I minute in group L and in group $\mathrm{S}$ is between 8-9and is not statistically significant. APGAR score at 5 minute in group $\mathrm{L}$ and in group $\mathrm{S}$ is and 10 is not statistically significant.

\section{Discussion}

Subarachnoid block is the anaesthesia technique of choice and is the gold standard for caesarean section. Levobupivacaine is a new long acting amide, local anaesthetic equipotent to bupivacaine ${ }^{8}$ and has a wide margin of safety and low cardio toxicity compared to bupivacaine. Data from non-obstetric patients cannot be directly extrapolated to obstetrics because of lower dose requirements in pregnancy. Parapaglioniet $\mathrm{al}^{13}$ using an up/down sequential allocation method determined that ED50 of levobupivacaine for a satisfactory obstetric subarachnoid block was $10.58 \mathrm{mg}$.In a study conducted by Goyal et al $^{14}$ fentanyl when added to isobaric levobupivacaine and hyperbaric bupivacaine in caesarean section showed shorter motor block time, decreased incidence of hypotension, bradycardia, early mobility of patients and no adverse effects on neonates.

By influencing the spread of local anaesthetic, maternal position may affect the speed of onset of sensory block. ${ }^{3,4}$ However studies of different maternal position have produced conflicting results. ${ }^{9,10}$ Park et $\mathrm{al}^{15}$ study shows that prolonged sitting posture after spinal anaesthesia using hyperbaric local anaesthetic can result in saddle block and urinary retention.

The mean onset of sensory block to T10 in group L was $3.62 \mathrm{~min}$ and in the group $\mathrm{S}$ was $3.77 \mathrm{~min}$ which in corroboration with the study by Vanna et $\mathrm{al}^{16}$ and Sen $\mathrm{H}$ et al. ${ }^{17}$ Vimolluck Sanaslipet al ${ }^{18}$ studied intrathecal isobaric compared to hyperbaric levobupivacaine $3 \mathrm{ml}$ $0.42 \%$ in gynecological lower abdominal surgery.

In the present study it was found that time for two dermatomal regression in group L was $80.96 \mathrm{~min}$ and in group $\mathrm{S}$ was $81.44 \mathrm{~min}$.In the studies by Guleret $\mathrm{al}^{19}$ and Goyal et $\mathrm{al}^{14}$ had results comparable to our study showing no changes in posture affects even on sensory regression time.

In the present study in group $\mathrm{L}$ mean time taken for regression to T10 was $157.12 \mathrm{~min}$ and in group was 157.92 min. Vimolluck Sanaslipet $\mathrm{al}^{18}$ studied intrathecal isobaric compared to hyperbaric levobupivacaine $3 \mathrm{ml} 0.42 \%$ in gynecological lower abdominal surgery, the mean time for regression to T10 for isobaric group is $160 \mathrm{~min}$.

In the present study mean and SD of time of motor onset in group L is $5.747 \mathrm{~min}$ and in group $\mathrm{S}$ is $\mathbf{5 . 8 7 6}$ min. 'P' value is 0.094 and is not significant. Guler et $\mathrm{al}^{19}$ compared $10 \mathrm{mg}$ isobaric levobupivacaine and $10 \mathrm{mg}$ hyperbaric bupivacaine in combination with fentanyl $15 \mathrm{mcg}$ intrathecally in caesarean section and time taken for motor onset was $4.1 \mathrm{~min}$ in the levobupivacaine group.

In our study in group L mean of total duration of motor block was $157.90 \mathrm{~min}$ and in group $\mathrm{S}$ was 158.52 mins. In Fabrio Gori et $\mathrm{al}^{9}$ study mean and SD of total duration of motor block in group L was 159 minutes and mean and SD of total duration of motor block in group $\mathrm{S}$ was 150 minutes. ' $\mathrm{P}$ ' value is 0.46 and was not significant and can be comparable to our study.

In our study in group L $4 \%$ of the patients had hypotension and in group S $6 \%$ of the patients had hypotension and $\mathrm{P}$ value was> 0.05 and is not significant. In the study Fabrio gori ${ }^{9}$ number of patients having hypotension are 19 in supine and 17 in sitting group.

In our study none of the patients had APGAR score less than 7. In Fabrio Gori ${ }^{9}$ study also all the patients in both sitting and lateral group APGAR score were 8-10 and which is comparable to our study. 


\section{Graph 1: Mean Time for Onset to T10 in minutes}

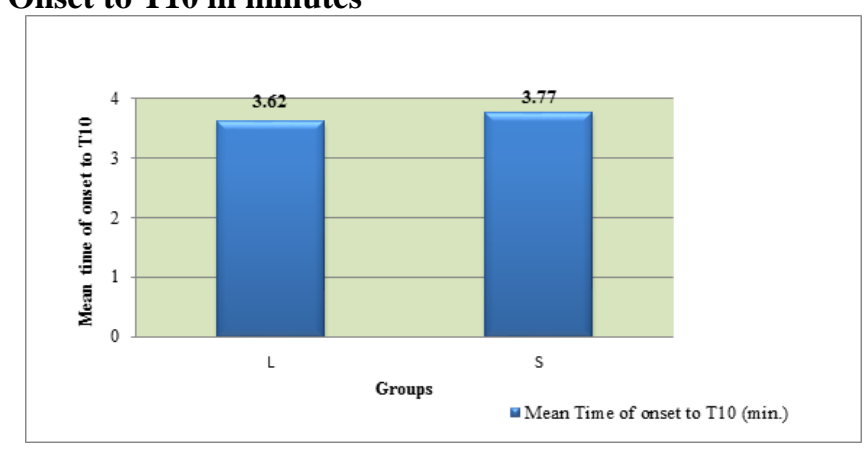

\section{Graph 2: Mean two dermatome regression}

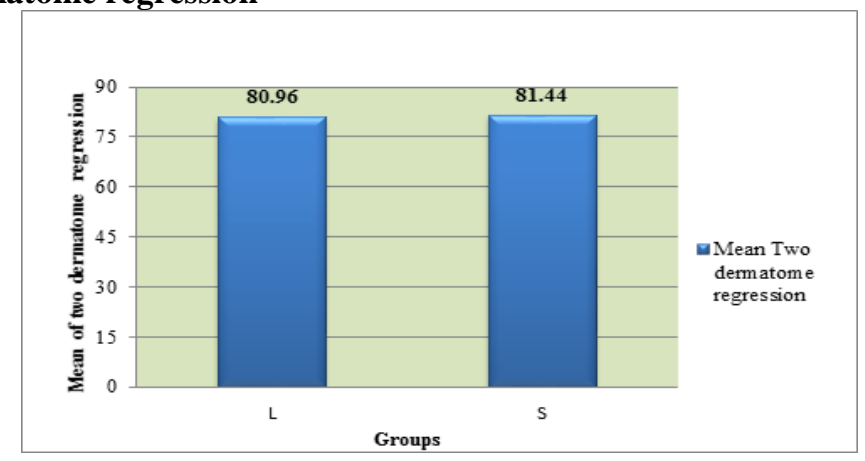

Graph 3: Regression T10 (min.) graph

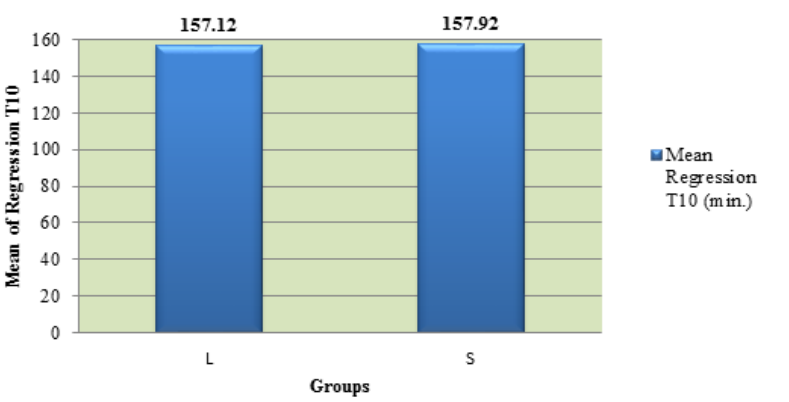

\section{Conclusion}

The present randomized control study concluded that $12.5 \mathrm{mg}$ dose of isobaric levobupivacaine $0.5 \%$ provides effective spinal anaesthesia, ensures good haemodynamic stability, excellent quality of sensory and motor block and no influence of gravity on the spread of plain levobupivacaine in sitting as well as lateral position. It can safely be used in sitting position and without fear of inadvertent extension after supine from sitting posture and block levels were distributed in a relatively narrow range with high success rate. Levobupivacaine may prove an excellent alternate to produce subarachnoid block for caesarean section.

\section{References}

1. Beer A. Experiments on cocaineising the backbone. Dtsch Ztschr Chir. 1899;51:361-9.

2. Gogarten W. Spinal anaesthesia for obstetrics, best Practice and research. Clinical Anaesthesiology.2003;17(3):377-92.
3. Edomwonyi NP, Ekwere IT, Egbekum,Idehen HO,Sadiq A. Anaesthesia related complications in obstetric patients. Afr J Anaesthesia intensive care. 2005;6:8-13.

4. Eberhart LH, Morin AM, Kranke P, Geldner G and Wulf $\mathrm{H}$. Transient neurologic symptoms after spinal anaesthesia: A quantitative systematic overview (metaanalysis) of randomized controlled studies. Anesthetist.2002;51:539-46.

5. Schneider M, Ettlin T, Kaufmann M, Schumacher P, Urwyler A, Hampl K, et al: Transient neurologic toxicity after hyperbaric anaesthesiawith 5\% lidocaine. AnesthAnalg. 1993;76:1154-7.

6. GristwoodRW. Cardiac and CNS toxicity of levobupivacaine: strengths of evidence for advantage over bupivacaine.Drug safety. 2002;25(3):153-63.

7. Shimizu R, Hirabayashi Y, Fukuda H. Soft tissue anatomy within vertebral canal in pregnant women. BJA.1996;77:153-6.

8. Hallworth SP, Fernando R, Columb MO, Stocks GM.The effect of posture and baricity on the spread of intrathecal bupivacaine for elective caesarean delivery.AnesthAnalg. 2005;100(4):1159-65. 
9. Gori F, Francesco C, Vittorio C, Vito A. Influence of positioning on plain levobupivacaine spinal anaesthesia in caesarean section. Anesthesiology Research and Practice.2010, Article ID 212696, 4 pages doi:10.1155/2010/212696.

10. Inglis A, Daniel M, Mc Gandy E. Maternal position during induction of spinal anaesthesia for caesarean section. A comparison of right lateral and sitting position.Anaesthesia.1995;50:363-5.

11. VicentO, Litz RJ, Hubler M, Koch T. Inadvertent cranial extension of a spinal block with isobaric $0.5 \%$ bupivacaine following late posture change. Der Anaesthesist. Nov 2003;52(11):1035-8.

12. Breen TW et al. Epidural anesthesia for labor in an ambulatory patient. AnesthAnalg 1993;77:919-24.

13. Parpaglioni R, Frigo MG, Lemna A, Celleno D, Sebastiani M, Barbati G. Minimum local anaestheticdose(MLAD) of intrathecal levobupivacaine and ropivacaine for caesarean section. Anaesthesia. 2006 Feb;61(2):110-5.

14. 14) Goyal A, Shankaranarayan P,Ganapathi P. A randomized clinical study comparing spinal anaesthesia with isobaric levobupivacaine with fentanyl and hyperbaric bupivacaine with fentanyl in elective caesarean sections. Anesth Essays Res. 2015;9(1): 57-62. doi: 10.4103/0259-1162.150169

15. Park SY, Park JC, Park SH.Is it useful and safe to maintain the sitting position during only one minute before position change to the Jack-knife position?.Korean J Pain. 2010;23(3):190-7.

16. Vanna O, Chumsang L, Thongmee S. Levobupivacaine and bupivacaine in spinal anaesthesia for transurethral endoscopic surgery. J Med Assoc Thai.2006;89(8):11339.

17. Sen H, Purtuloglu T, Sizlan A, Yanarates O, Ates F, Gundu I, et al. Comparison of intrathecal hyperbaric and isobaric levobupivacaine in urological surgery. Minerva Anestesiol. 2010;76(1):24-8.

18. Sanansilp V, Trivate T, Chompubai P, Visalyaputra S, Suksopee P, Permpolprasert L, et al.Clinical characteristics of spinal levobupivacaine: hyperbaric compared with isobaric solution. The Scientific World Journal.2012 (2012), Article ID 169076,7 pages.http://dx.doi.org/10.1100/2012/169076.

19. Guler G, Gokhan C, Ayse U, Fatih U. A comparison of spinal anaesthesia with levobupivacaine and hyperbaric bupivacaine for caesarean sections. Open Journal of Anesthesiology.2012;2:84-9. 